\title{
Structure-Activity Relationships of Alkylxanthines: Alkyl Chain Elongation at the N1- or N7-Position Decreases Cardiotonic Activity in the Isolated Guinea Pig Heart
}

\author{
Fujiko Sanae $^{1}$, Shinji Ohmae ${ }^{1}$, Mariko Kurita ${ }^{1}$, Hiroyuki Sawanishi ${ }^{2}$, Kenzo Takagi $^{3}$ and Ken-ichi Miyamoto ${ }^{1, *}$ \\ Departments of 'Applied Pharmacology and ${ }^{2}$ Synthetic Chemistry, Faculty of Pharmaceutical Sciences, Hokuriku University, \\ Ho-3 Kanagawa-machi, Kanazawa 920-11, Japan \\ ${ }^{3}$ 2nd Department of Internal Medicine, Nagoya University School of Medicine, Showa-ku, Nagoya 466, Japan
}

Received May 24, 1995 Accepted June 28, 1995

\begin{abstract}
Relationships between the alkyl substitutions $\left(C_{1}-C_{6}\right)$ and cardiac inotropic activities of xanthine derivatives were studied in isolated guinea pig heart muscles. Most of the alkylxanthines exhibited positive inotropic activity on the left atrium, which was increased with an elongation of alkyl chain at the N3-position but decreased by substitution of a long alkyl group at the N1- or N7-position of the xanthine skeleton. Although positive inotropic activity in the right ventricular papillary muscle was also increased by longer alkyl groups at the N3-position, the inotropic activity became negative with an increment in alkyl chain length at the N1- or N7-position. The positive inotropic activity of alkylxanthines was correlated with their inhibitory activity on the phosphodiesterase (PDE) III isoenzyme. Adenosine $\mathrm{A}_{1}$ antagonism and PDE IV inhibitory activity were also partly associated with the inotropic activity because $\mathrm{H}-89$, an inhibitor of cyclic AMP-dependent protein kinase, diminished the positive inotropic action and potentiated the negative inotropic action. These results indicate that the positive inotropic activity of alkylxanthines becomes weak with elongation of alkyl chains at the N1- and N7-positions; In particular, xanthines having two long alkyl chains show a negative inotropic activity on the right ventricular papillary muscle, an effect that could not be elucidated from their cyclic AMP-dependent action.
\end{abstract}

Keywords: Structure-activity relationship, Alkylxanthine, Cardiac inotropic activity, Phosphodiesterase isoenzyme, Adenosine

Pharmacological actions of methylxanthines, such as theophyline, have been appreciated from their non-selective phosphodiesterase (PDE) inhibition $(1,2)$ and adenosine antagonism $(3,4)$. In our previous studies on structure-activity relationships of alkylxanthine derivatives (5-9), we indicated that the tracheal relaxant activity increased with elongation of the alkyl chain at the N1-, N3- and N7-positions of the xanthine skeleton, and the activity was closely correlated with their inhibitory activity on the PDE IV isoenzyme but not with the adenosine $A_{1}$ affinity. On the other hand, the positive chronotropic action of xanthine derivatives on the right atrium was decreased with the alkyl chain length at the N1- and N7-positions and correlated with their PDE III inhibitory activity $(6,8)$. In this study, we further examined the effects of alkyl substitutions of the xanthine

* To whom correspondence should be addressed. skeleton on the inotropic activities of the isolated guinea pig heart, and we discussed the correlations with PDE inhibitory activity and adenosine antagonism of a series of alkylxanthines.

\section{MATERIALS AND METHODS}

\section{Materials}

A series of alkylxanthines, XT-012 (3-ethyl-1methylxanthine), XT-010 (1-methyl-3-n-propylxanthine), XT-011 (3-n-butyl-1-methylxanthine), enprofylline (3-npropylxanthine), XT-015 (1-ethyl-3-n-propylxanthine), XT-043 (1,3-di- $n$-propylxanthine), XT-044 (1- $n$-butyl-3$n$-propylxanthine), XT-045 (1-n-pentyl-3-n-propylxanthine), XT-046 (1- $n$-hexyl-3-n-propylxanthine), XT-017 (1,7-dimethyl-3-n-propylxanthine), XT-074 (7-ethyl-1methyl-3-n-propylxanthine), XT-075 (1-methyl-3,7-di- $n$ propylxanthine), XT-077 (7-n-butyl-1-methyl-3-n-propyl- 
Table 1. Structures of xanthine derivatives

\begin{tabular}{lccc}
\hline & & \\
Compound & & $\mathrm{R}^{1}$ &
\end{tabular}

Me, methyl; Et, ethyl; $n$-Pro, normal propyl; $n$-Bu, normal butyl; $n$-Pen, normal pentyl; $n$-Hex, normal hexyl; 8-c-Pen, 8-cyclopentyl; 2'-Oxopro, 2'-oxopropyl.

xanthine) and denbufylline (1,3-di- $n$-butyl-7-(2'-oxopropyl)xanthine) were synthesized at Department of Synthetic Chemistry, Faculty of Pharmaceutical Sciences, Hokuriku University $(6,10)$, and their structures are shown in Table 1. Other agents used were: theophylline, amrinone, isoprenaline, adenosine, cyclic AMP, cyclic GMP (Sigma Chemical Co., St. Louis, MO, USA), 8-cyclopentyl-1,3-di- $n$-propylxanthine (DPCPX), Ro 20-1724 (Research Biochemicals Inc, Natick, MA, USA), $N$ [2-( $p$-bromocinnamylamino)ethyl]-5-isoquinolinesulfonamide (H-89; Seikagaku Kogyo Co., Tokyo), $\left[{ }^{3} \mathrm{H}\right]$ cyclic AMP $(1.2 \mathrm{GBq} / \mu \mathrm{mol})$ and $\left.{ }^{3} \mathrm{H}\right] \mathrm{DPCPX}(4.0 \mathrm{GBq} / \mu \mathrm{mol})$ (New England Nuclear, Boston, MA, USA). Theophylline and enprofylline were dissolved in distilled water. An initial stock solution of other xanthine derivatives, amrinone and Ro 20-1724 was prepared by dissolving each in dimethyl sulfoxide (DMSO). Aliquots of the stock solution were then diluted in distilled water. The final concentration of DMSO used in each assay was below $1 \%$, a concentration at which the pharmacological responses were barely influenced. Isoprenaline was dissolved in 0.57 $\mathrm{mM}$ ascorbic acid solution.

\section{Animals}

Male Hartley guinea pigs weighing $300-500 \mathrm{~g}$ (Nippon
SLC, Hamamatsu) were used. To sacrifice the animals, they were first stunned and then bled, and their heart muscles were rapidly removed.

Contractile responses of the left atrium and the right ventricular papillary muscle

The left atrium and the right ventricular papillary muscle (diameter $<1 \mathrm{~mm}$, length $3-6 \mathrm{~mm}$ ) were dissected from the heart carefully. The preparation was mounted under $0.5 \mathrm{~g}$ of resting tension in an organ bath $\left(30^{\circ} \mathrm{C}\right)$ containing $10 \mathrm{ml}$ of Krebs-Henseleit solution aerated with a gas of $95 \% \mathrm{O}_{2}-5 \% \mathrm{CO}_{2}$ and was stimulated by rectangular pulses of $1 \mathrm{~Hz}$ frequency, $1 \mathrm{msec}$ in duration and 1.5 times the threshold voltage, delivered by bipolar platinum stimulating electrodes connected to an electronic stimulator (SEN-7203; Nihon Kohden, Tokyo). Isometric tension developed in the preparation was measured with a force transducer (T7-30-240; Orientec, Tokyo) and recorded. The preparation was allowed to equilibrate for $60 \mathrm{~min}$ before the experiments were begun. The concentration-response curve for the inotropic effect of a compound was determined in a cumulative manner. It was confirmed that the positive or negative inotropic effect of each concentration of the compound was maintained at a steady level for at least $15 \mathrm{~min}$ after administration. Data were expressed as the concentration causing a $20 \%$ increase or decrease $\left(\mathrm{EC}_{20}\right)$ relative to the untreated contractile force.

To examine the effects of xanthine derivatives on the inotropic responses to adenosine and isoprenaline, the concentration-response curve for the effect of adenosine or isoprenaline was determined in a cumulative manner in the preparation pretreated with each compound for 20 min. An application of adenosine was done in the presence of $10 \mu \mathrm{M}$ dipyridamole to inhibit the uptake of adenosine in the preparation (11). When an inhibitor of cyclic AMP-dependent protein kinase (PK-A), H-89 (12), was used, it was added to the organ bath 15 min before the administration of the xanthine derivatives.

\section{Adenosine receptor binding assay}

Preparation of the membranes from the cerebral cortex and the adenosine $A_{1}$-receptor-selective ligand $\left[{ }^{3} \mathrm{H}\right]$ DPCPX (13) binding assay was done basically as described by Jacobson and co-workers (14) and ourselves (15). The nonlinear least-square method was used to fit the concentration-inhibition data for each compound to a model of competitive inhibition. The inhibition constant, $K_{i}$, was calculated from the Cheng-Prusoff equation (16).

\section{$P D E$ inhibition assay}

$\mathrm{Ca}^{2-} /$ calmodulin-stimulated cyclic AMP PDE (type I, $\mathrm{K}_{\mathrm{m}}=5.4 \mu \mathrm{M}$ and $\mathrm{V}_{\max }=2.4 \mathrm{nmol} / \mathrm{min}$ per $\mathrm{mg}$ protein) 
and cyclic AMP-specific PDE (type IV, $\mathrm{K}_{\mathrm{m}}=2.9 \mu \mathrm{M}$ and $\mathrm{V}_{\max }=0.85 \mathrm{nmol} / \mathrm{min}$ per $\mathrm{mg}$ protein) from the cerebral cortex and cyclic GMP-inhibited cyclic AMP PDE (type III, $\mathrm{K}_{\mathrm{m}}=0.67 \mu \mathrm{M}$ and $\mathrm{V}_{\max }=1.2 \mathrm{nmol} / \mathrm{min}$ per $\mathrm{mg}$ protein) from the heart ventricle were isolated according to the method reported by Reeves et al. (17) and used in the experiments. The enzyme preparation and various concentrations of a compound were incubated at $30^{\circ} \mathrm{C}$ for $10 \mathrm{~min}$, and the PDE activity was assayed by the method of Thompson and Appleman (18). The concentration producing $50 \%$ inhibition of cyclic AMP hydrolysis $\left(\mathrm{IC}_{50}\right)$ for each PDE isoenzyme was calculated by the nonlinear least-square method.

\section{Statistics}

Values are given as the means \pm S.E. of three to five measurements. The regression lines were calculated with the program for the nonlinear least-square method (MULTI) of Yamaoka et al. (19). Statistical significance was calculated by Student's $t$-test and Welch's $t$-test.

\section{RESULTS}

\section{Inotropic activity on the left atrium}

Most of the alkylxanthines increased the contractile force of the left atrium in a concentration-dependent

Table 2. Effects of xanthine derivatives on the left atrium

\begin{tabular}{lcc}
\hline Compound & $\begin{array}{c}\text { Positive } \\
\text { inotropic action } \\
\mathrm{EC}_{20}(\mu \mathrm{M})\end{array}$ & $\begin{array}{c}\text { Adenosine } \\
\text { antagonism } \\
\mathrm{pA}_{2}^{\mathrm{a}}\end{array}$ \\
\hline Theophylline & $>100^{\mathrm{b})}$ & 4.75 \\
XT-012 & $54.1 \pm 5.5$ & 4.75 \\
XT-010 & $14.0 \pm 3.1$ & 6.03 \\
XT-011 & $5.0 \pm 0.9$ & 5.45 \\
Enprofylline & $23.4 \pm 5.8$ & 4.38 \\
XT-015 & $16.4 \pm 3.6$ & 5.98 \\
XT-043 & $81.2 \pm 16.0$ & 5.81 \\
XT-044 & $91.7 \pm 8.7$ & 6.06 \\
XT-045 & $>100^{\mathrm{b})}$ & 5.26 \\
XT-046 & $>100^{\mathrm{b})}$ & 4.88 \\
XT-017 & $54.1 \pm 4.0$ & 5.86 \\
XT-074 & $63.1 \pm 0.1$ & 5.29 \\
XT-075 & $56.2 \pm 5.0$ & 4.74 \\
XT-077 & $62.2 \pm 18.8$ & 5.17 \\
DPCPX & $10.4 \pm 1.0$ & 8.64 \\
Denbufylline & $12.2 \pm 2.1$ & 5.09 \\
Amrinone & $39.9 \pm 5.9$ & - \\
Ro 20-1724 & $>100^{\mathrm{b}\}}$ & - \\
\hline
\end{tabular}

Data are the means \pm S.E. of at least three experiments. ${ }^{a} \mathrm{pA}_{2}$ values are the means of three experiments. ${ }^{b} 20 \%$ increase in the cardiac action was not found at $100 \mu \mathrm{M}$, the maximum concentration soluble in the assay buffer. manner, and the $20 \%$ increasing concentrations $\left(\mathrm{EC}_{20}\right)$ are listed in Table 2. Theophylline exhibited a weak positive inotropic activity, and substitution with a long alkyl chain at the N3-position increased the activity. Additional alkyl elongation at the N1-position decreased or diminished the positive inotropic activity. Alkylation at the N7-position of XT-010 also decreased the activity. Although DPCPX and denbufylline had long alkyl chains, such as $n$-propyl and $n$-butyl groups, at both the N1- and N3-positions, these inotropic activities were relatively strong, compared to those of the simple alkylxanthines. Regarding the non-xanthine PDE inhibitors, amrinone, a PDE III inhibitor (20), exhibited less inotropic action than XT-010, and Ro 20-1724, a PDE IV inhibitor (17), had little effect.

\section{Inotropic activity on right ventricular papillary muscle}

When the alkyl chain length at the N3-position of theophylline was elongated, the positive inotropic activity was increased. However, the substitutions with long alkyl chains at the N1- and N-7-positions induced negative inotropic activity (Table 3, Fig. 1). This was particularly pronounced with an increase in alkyl chain length at the

Table 3. Effects of xanthine derivatives on the right ventricular papillary muscle

\begin{tabular}{|c|c|c|c|}
\hline Compound & \multicolumn{2}{|c|}{$\begin{array}{c}\text { inotropic action } \\
\mathrm{EC}_{20}(\mu \mathrm{M})\end{array}$} & $\begin{array}{l}\text { Potentiation ratio } \\
\text { of } \\
\text { isoprenaline action }^{\text {a) }}\end{array}$ \\
\hline Theophylline & $>100^{\mathrm{by}}$ & - & 1.5 \\
\hline XT-012 & $19.4 \pm 7.2$ & - & 1.8 \\
\hline XT-010 & $6.8 \pm 1.5$ & - & 2.9 \\
\hline XT-011 & $3.6 \pm 0.8$ & - & 2.4 \\
\hline Enprofylline & $44.7 \pm 2.4$ & - & 1.9 \\
\hline XT-015 & $44.5 \pm 4.6$ & - & 1.6 \\
\hline XT-043 & - & $75.0 \pm 6.4$ & 1.6 \\
\hline XT-044 & - & $67.7 \pm 5.8$ & 1.3 \\
\hline XT-045 & - & $55.5 \pm 1.1$ & 1.1 \\
\hline XT-046 & - & $36.9 \pm 3.1$ & 0.9 \\
\hline XT-017 & $>100^{\mathrm{h})}$ & - & 2.2 \\
\hline XT-074 & $48.5 \pm 8.5$ & - & 1.5 \\
\hline XT-075 & $>100^{\mathrm{bj}}$ & - & 2.0 \\
\hline XT-077 & - & $47.7 \pm 7.6$ & 1.4 \\
\hline DPCPX & - & $26.4 \pm 0.2$ & 1.1 \\
\hline Denbufylline & - & $24.1 \pm 5.4$ & 1.7 \\
\hline Amrinone & $28.3 \pm 3.2$ & - & 2.4 \\
\hline Ro $20-1724$ & none $e^{c)}$ & none $e^{c y}$ & 1.9 \\
\hline
\end{tabular}

Data are the means \pm S.E. of at least three experiments. ${ }^{\text {a) }}$ Positive inotropic action of isoprenaline $\left(\mathrm{EC}_{50}\right)$ vs that after pretreatment with a compound $(10 \mu \mathrm{M})$. Values are the means of at least three experiments. ${ }^{b} 20 \%$ increase in the cardiac action was not found at $100 \mu \mathrm{M}$, the maximum concentration soluble in the assay buffer. ${ }^{c}$ No inotropic actions were observed. 


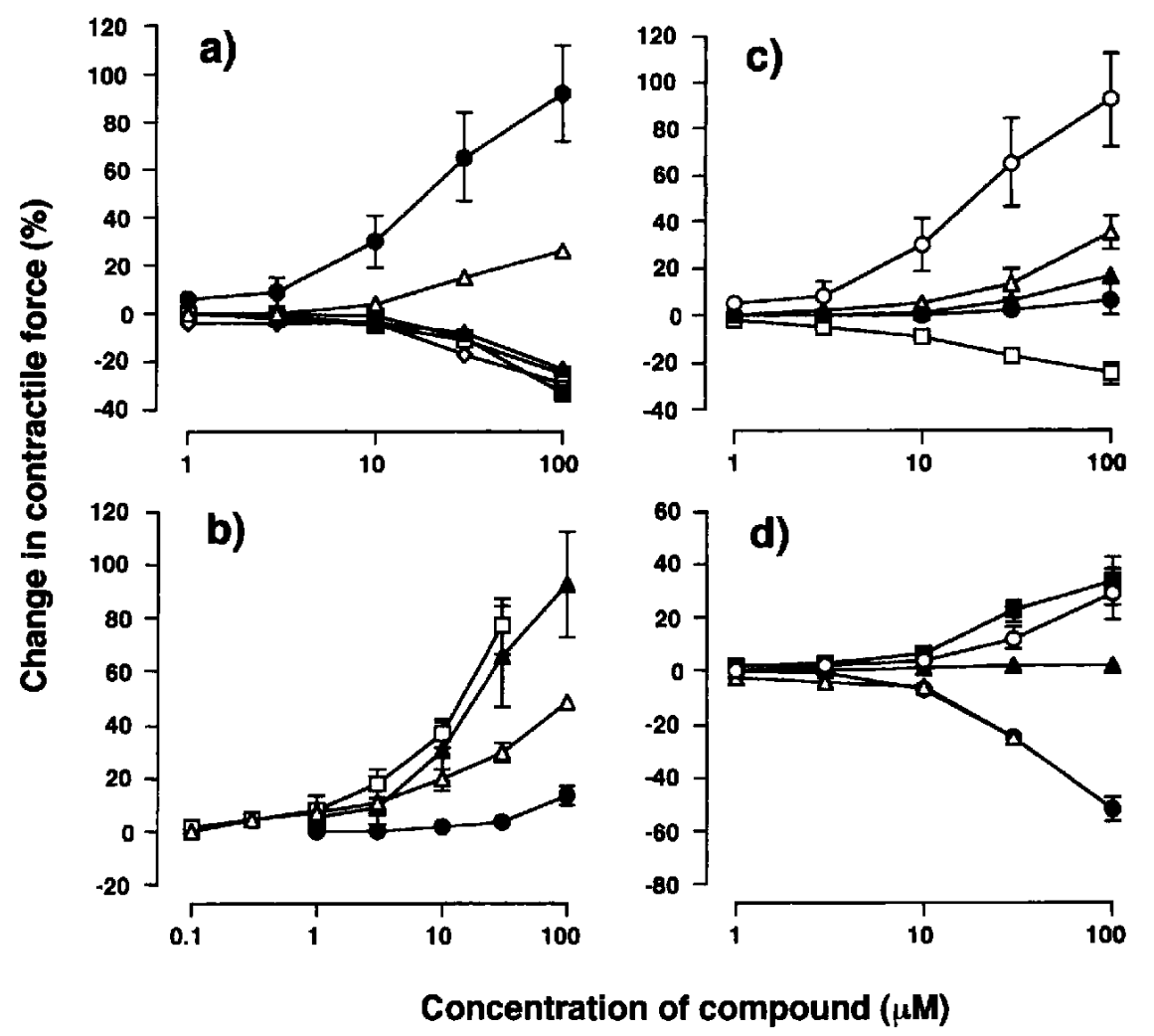

Fig. 1. Inotropic activities of alkylxanthines and PDE inhibitors on the right ventricular papillary muscle. a: 1-Substituted 3n-propylxanthines, b: 3-substituted 1-methylxanthines, c: 7-substituted 1-methyl-3-n-propylxanthines; In panels a to $c$, symbols represent: $\bigcirc$, methyl-; $\triangle$, ethyl-; $\boldsymbol{\Lambda}, n$-propyl-; $\square$, n-butyl-; $\boldsymbol{\square}, n$-pentyl-; $\diamond, n$-hexyl-substituents. d: Related xanthines: $\bigcirc$, enprofylline; $\triangle$, DPCPX;, denbufylline, and PDE inhibitors: $\square$, amrinone; $\boldsymbol{\Delta}$, Ro 20-1724. Data are the means \pm S.E. (bar) of at least three experiments.

N1-position.

\section{Adenosine antagonism}

Adenosine showed a negative inotropic effect on the left atrium but did not affect the papillary muscle. All alkylxanthines antagonized the effect of adenosine on the left atrium in a concentration-dependent manner. The $\mathrm{pA}_{2}$ values of alkylxanthines are shown in Table 2. There was a good correlation between the $\mathrm{pA}_{2}$ value and the adenosine $A_{1}$ affinity for brain membranes, shown in Table 4 ( $\mathrm{r}=0.854, \mathrm{P}<0.05)$ (Fig. 2).

Effect on the contractile response to isoprenaline in right ventricular papillary muscle

Isoprenaline increased the contraction of papillary muscle. The positive inotropic effect of isoprenaline was potentiated by pretreatment with xanthine derivatives and PDE inhibitors, and the potentiation ratio by $10 \mu \mathrm{M}$ of each compound is shown in Table 3. Although elongation of the alkyl chain at the N3-position of theophylline markedly potentiated the response of the muscle to isoprenaline and XT-010 showed a more potent effect, further substitution of long alkyl chains at the N1- or N7-position of the xanthine skeleton tended to decrease the potentiation effect of XT-010. Amrinone, denbufylline and Ro 20-1724 also potentiated the effect of isoprenaline by about twofold.

Correlations between the PDE inhibitory activities and the inotropic activities

Table 4 shows the inhibitory activities of XT-045 and XT-046, measured in this study, and those of other xanthine derivatives and PDE inhibitors, reported previously $(8,9)$, on PDE I and IV from the brain and PDE III from the heart. There was a good correlation between the PDE III inhibitory activity and the positive inotropic activity on the left atrium $(r=0.915, P<0.05)$ (Fig. 3a). Furthermore, the PDE III inhibitory activity of alkylxanthines showing positive inotropic action on the ventricular papillary muscle was also closely correlated to their inotropic activity ( $\mathrm{r}=0.858, \mathrm{P}<0.05)$ (Fig. 3b). There were no relationships between the inhibitory activities on other PDE isoenzymes and the inotropic activities, except for the xanthine derivatives, which caused negative ino- 
Table 4. Affinity for the adenosine $A_{1}$ receptor of brain membrane and inhibitory activities on PDE isoenzymes

\begin{tabular}{|c|c|c|c|c|}
\hline \multirow{2}{*}{ Compound } & \multirow{2}{*}{$\begin{array}{c}\text { Affinity for } \\
\mathbf{A}_{1} \text { receptor } \\
\left(\mathrm{K}_{\mathrm{i}}, \mu \mathrm{M}\right)\end{array}$} & \multicolumn{3}{|c|}{ Inhibitory activity $\left(\mathrm{IC}_{50}, \mu \mathrm{M}\right)$ on } \\
\hline & & PDE I & PDE III & PDE IV \\
\hline Theophylline $\mathrm{e}^{\mathrm{b}\}}$ & $9.8 \pm 0.4$ & $356 \pm 46$ & $240 \pm 21$ & $80.7 \pm 6.4$ \\
\hline $\mathrm{XT}-012^{\mathrm{c}, \mathrm{d})}$ & $7.6 \pm 1.2$ & $51.0 \pm 5.0$ & $55.4 \pm 5.6$ & $25.1 \pm 4.8$ \\
\hline $\mathrm{XT}-010^{\mathrm{b})}$ & $1.9 \pm 0.2$ & $21.0 \pm 2.6$ & $13.7 \pm 2.0$ & $3.2 \pm 1.3$ \\
\hline $\mathrm{XT}-011^{\mathrm{b})}$ & $1.9 \pm 0.03$ & $7.5 \pm 3.3$ & $13.2 \pm 1.9$ & $2.7 \pm 0.7$ \\
\hline Enprofylline $^{\mathrm{b})}$ & $60.7 \pm 4.6$ & $695 \pm 81$ & $31.8 \pm 6.9$ & $22.0 \pm 3.9$ \\
\hline $\mathrm{XT}-015^{\mathrm{c}, \mathrm{d})}$ & $1.4 \pm 0.6$ & $55.7 \pm 7.6$ & $37.3 \pm 5.5$ & $3.1 \pm 1.1$ \\
\hline$X T-043^{b)}$ & $0.20 \pm 0.10$ & $95.3 \pm 7.3$ & $347 \pm 68$ & $0.59 \pm 0.19$ \\
\hline $\mathrm{XT}-044^{\mathrm{c}, \mathrm{d})}$ & $0.02 \pm 0.01$ & $149 \pm 12$ & $>300(30 \%)^{\mathrm{a})}$ & $0.34 \pm 0.07$ \\
\hline XT-045 & $0.58 \pm 0.02$ & $131 \pm 15$ & $>300(17 \%)^{\mathrm{a})}$ & $0.17 \pm 0.05$ \\
\hline XT-046 & $1.2 \pm 0.4$ & $77.0 \pm 2.1$ & $>300(6 \%)^{\mathrm{a})}$ & $0.11 \pm 0.04$ \\
\hline $\mathrm{XT}-017^{\mathrm{c}, \mathrm{d} \mathfrak{}}$ & $14.5 \pm 0.2$ & $176 \pm 53$ & $>300(5 \%)^{\mathrm{a})}$ & $13.9 \pm 1.2$ \\
\hline $\mathrm{XT}-074^{c, \mathrm{~d}}$ & $14.2 \pm 1.8$ & $26.3=2.8$ & $>300(41 \%)^{\mathrm{a})}$ & $4.3 \pm 0.5$ \\
\hline $\mathrm{XT}-075^{\mathrm{b})}$ & $9.4 \pm 5.1$ & $16.5 \pm 2.9$ & $218 \pm 21$ & $5.6 \pm 1.8$ \\
\hline $\mathrm{XT}-077^{\mathrm{c}, \mathrm{d})}$ & $7.3 \pm 0.7$ & $7.4 \pm 1.7$ & $>300(23 \%)^{a)}$ & $17.4=4.8$ \\
\hline $\mathrm{DPCPX}^{\mathrm{b})}$ & $0.26 \pm 0.05(\mathrm{nM})$ & $>300(0 \%)^{a)}$ & $>300 \quad(0 \% 0)^{a)}$ & $2.0 \pm 0.6$ \\
\hline Denbufylline $e^{b]}$ & $16.5 \pm 4.0$ & $209 \pm 18$ & $>300 \quad(0 \% /)^{a)}$ & $0.07 \pm 0.02$ \\
\hline Amrinone $\mathrm{e}^{\mathrm{b})}$ & - & $>300(21 \%)^{a)}$ & $12.9 \pm 2.7$ & $101 \pm 1$ \\
\hline Ro $20-1724^{\text {b) }}$ & - & $>300(17 \%)^{a)}$ & $>300(42 \%)^{a)}$ & $0.24 \pm 0.06$ \\
\hline
\end{tabular}

Data are the means \pm S.E. of three to five experiments. ${ }^{\text {a) }} 50 \%$ inhibition of enzyme activity was not found at $300 \mu \mathrm{M}$, the maximum concentration soluble in the assay mixture, and in parentheses is indicated the $\%$ inhibition at $300, \mu \mathrm{M}$ of each compound. ${ }^{\mathrm{b}, c, d)}$ Data from our previous papers, reference numbers 8,6 and 9 , respectively.

tropism and contained relatively potent $\mathrm{PDE}$ IV inhibitors. Ro 20-1724, a selective PDE IV inhibitor having a non-xanthine structure, did not influence the contractile force of the papillary muscle (Table 3 and Fig. 1).

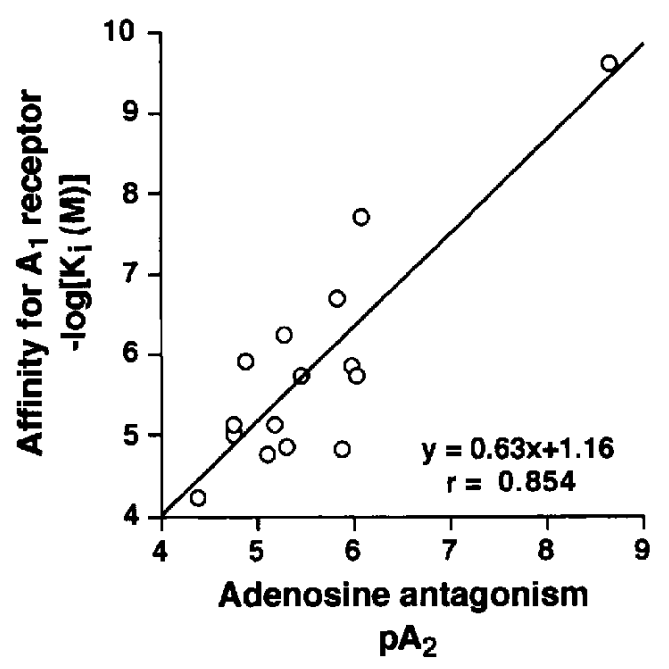

Fig. 2. Correlation between the adenosine antagonism on the left atrium and the $A_{1}$ affinity for brain membrane. The $\mathrm{pA}_{2}$ value is from Table 2 and the $A_{1}\left(K_{i}\right)$ is from Table 4.
Effect of $H-89$ on the inotropic action

The PK-A inhibitor $\mathrm{H}-89$ caused negative inotropism on the left atrium and the right ventricular papillary muscle in a concentration-dependent manner, and it decreased the contractile force by $35 \%$ of the basal contraction at $100 \mu \mathrm{M}$. When pretreated with $1 \mu \mathrm{M}$ H-89, a concentration that barely influenced the contractile force of heart tissues, the positive inotropic actions of xanthine derivatives and PDE inhibitors were significantly diminished (Fig. 4). Moreover, the negative inotropic actions of XT-044 $(100 \mu \mathrm{M}), \mathrm{XT}-077(100 \mu \mathrm{M})$ and denbufylline $(30 \mu \mathrm{M})$ on papillary muscle were further increased by H-89 (Fig. 4b). Although Ro 20-1724 (100 $\mu \mathrm{M})$ alone had no effect on papillary muscle, a mild negative inotropism appeared in the presence of H-89.

\section{DISCUSSION}

Methylxanthines, such as caffeine and theophylline, have a variety of pharmacological activities. We have studied structure-activity relationships of alkylxanthine derivatives $(5-10,15)$. In these studies, we indicated that the tracheal relaxant activity was increased by substitutions of long alkyl chains at both the N1- and N3-positions of the xanthine skeleton and was closely related to 
a) Left atrium

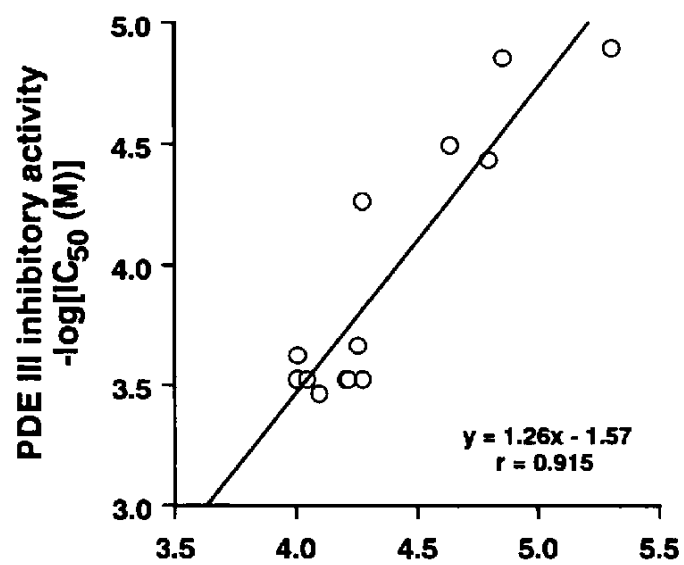

b) Papillary muscle

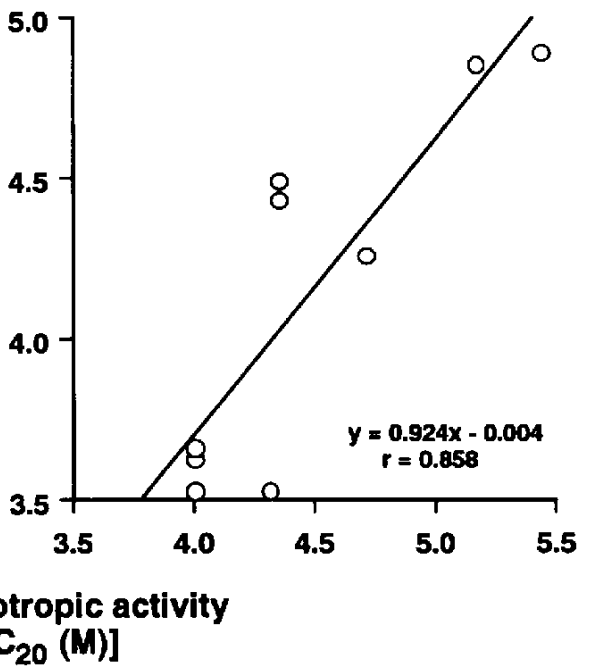

Fig. 3. Correlations between the positive inotropic activity on the left atrium (a) or that on the right ventricular papillary muscle (b) and PDE III inhibitory activity of alkylxanthines.

their PDE IV inhibitory activity. Regarding cardiac action, reports of structure-activity relationships are limited. Our previous studies have shown that the positive chronotropic activity of alkylxanthines in the right atrium of guinea pigs was decreased by substitutions at N1- and N7-positions, with a good correlation with their PDE III inhibitory activity $(6,8)$. In this study using a series of $1,3,7$-alkylxanthines, the positive inotropic activity in the left atrium was increased with an elongation of the alkyl chain at the N3-position and decreased by long alkyl substitution at the N1- or N7-position (Table 2), showing a similar result for the chronotropic activity on the right atrium (6). On the other hand, although the positive inotropic activity in the right ventricular papillary muscle was also increased with the alkyl chain elongation at the N3-position, the inotropic activity became negative with an increase in the alkyl chain length at the N1- or N7-position of the xanthine skeleton (Table 3, Fig. 1). To our knowledge, this is the first report of xanthine derivatives exhibiting negative inotropic action.

Differences in bulk tolerance, long distance, and hydrophobicity may modify the interaction betweeen the xanthine molecule and its binding regions in the enzyme or receptor molecule. The long alkyl groups bind to the $\mathrm{N}^{3}$ region in every PDE isoenzyme molecule, and the bulk tolerance limits the molecular interaction at both the $\mathrm{N}^{1}$ and $\mathrm{N}^{7}$ regions in PDE III. Consequently, the positive inotropic activities of alkylxanthines on both the left atrium and ventricular papillary muscle were closely correlated with their PDE III inhibitory activity (Fig. 3), like what was observed for other cardiotonic agents (20). However, even xanthine derivatives, which barely inhibited PDE III, exhibited a weak positive inotropic action, and these compounds had high PDE IV inhibitory activity and adenosine $A_{1}$ antagonistic activity (Table 4 ). Because of the presence of PDE IV isoenzyme in the heart $(17,20)$, these compounds may act through cyclic AMP elevation by inhibiting this enzyme. On the other hand, adenosine acts on the inhibitory receptor $\left(A_{1}\right)$ coupled with adenylate cyclase and acts as an endogenous modulator of the contractile force of the heart $(21,22)$. Therefore, adenosine antagonists are thought to increase the intracellular cyclic AMP level in the heart. Indeed, the positive inotropic activity of xanthine derivatives was significantly inhibited by a PK-A inhibitor H-89 (Fig. 4), indicating that PDE III inhibition plays a major role in the activation of the cyclic AMP-PK-A pathway, while PDE IV inhibition or $A_{1}$ antagonism plays a relatively minor one in the positive inotropic action.

Some alkylxanthine derivatives having two long alkyl groups, including DPCPX and dendufylline, showed negative inotropic activity on the right ventricular papillary muscle (Fig. 1). These negative activities were further potentiated by pretreatment with $\mathrm{H}-89$ (Fig. 4). These results suggest that these compounds possess a latent positive inotropic action. All alkylxanthine derivatives and PDE III and PDE IV inhibitors potentiated, but never inhibited, the effect of isoprenaline. From these results, inhibitory activity on not only the PDE III isoenzyme but the PDE IV isoenzyme may elicit the contractile force of cardiac muscles through elevation of the cyclic AMP level in myocytes. It is difficult to elucidate the ino- 


\section{a) Left atrium}

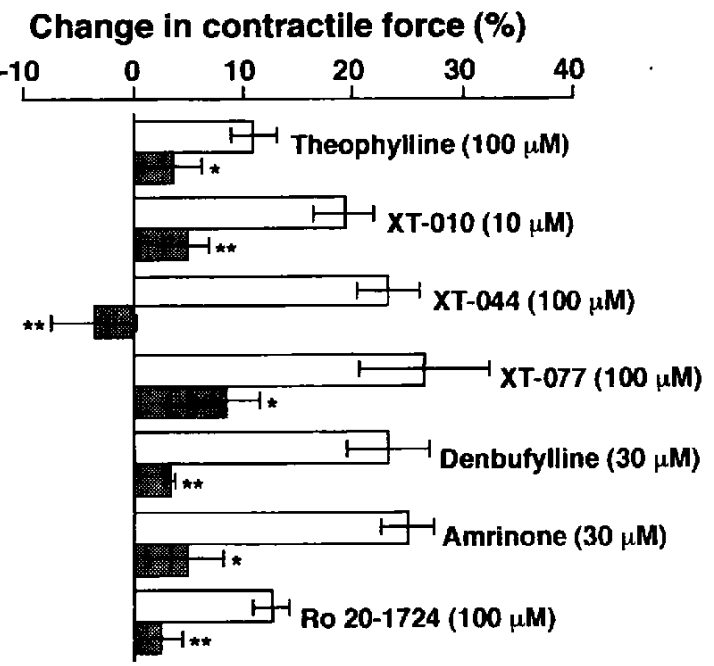

\section{b) Papillary muscle}

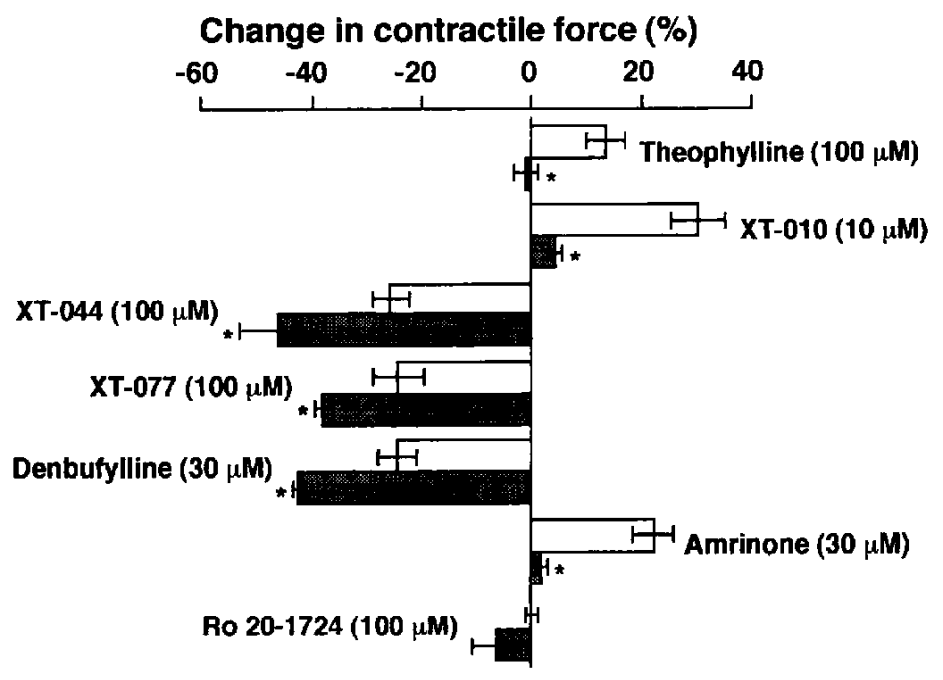

Fig. 4. Effect of H-89 on inotropic activity of xanthine derivatives and PDE inhibitors in the left atrium (a) and the right ventricular papillary muscle (b). Tissues were treated with a compound at the concentration indicated in parentheses in the absence (open column) or presence of $\mathrm{H}-89$ (dotted column), added $15 \mathrm{~min}$ before. Data are the means \pm S.E. (bar) of three to five experiments. ***:Significantly different from compound alone at $\mathbf{P}<0.05$ and $\mathbf{P}<0.01$, respectively.

tropic activity of xanthine derivatives on the ventricular papillary muscle from their adenosine $\mathbf{A}_{1}$ antagonism, because the tissue does not respond to adenosine $(22,23)$. The exact mechanisms of the negative inotropic action of alkylxanthine derivatives, therefore, remain unclear, and further studies are needed to elucidate them. Because these compounds possess in common two long alkyl groups in the xanthine molecule, these moieties may interact with the contraction-related proteins, such as ion channels, in ventricular myocytes.

In conclusion, the positive inotropic activity of xan- thine derivatives was increased with an elongation of the alkyl chain at the N3-position, but decreased in the left atrium, and they became negative in ventricular papillary muscle when long alkyl groups were substituted at the N1and N7-positions. The positive inotropic activity of alkylxanthines appears to be mainly due to their inhibition of PDE III, but the negative inotropic activity may involve mechanisms independent of cyclic AMP-mediated actions. 


\section{REFERENCES}

1 Blinks JR, Olson CB, Jewell BR and Bravery O: Influence of caffeine and other methyl xanthines on mechanical properties of isolated mammalian heart muscle. Evidence for a dual mechanism of action. Circ Res 30, 367-392 (1972)

2 Samer MS and Kreighbaum WE: Cyclic nucleotide phosphodiesterases: properties, activators, inhibitors, structure-activity relationships and possible role in drug development. J Pharm Sci 64, 1-37 (1975)

3 Jahnel U and Nawrath $\mathrm{H}$ : Characterization of adenosine receptors in guinea pig isolated left atria. Br J Pharmacol 97, 1182-1190 (1989)

4 Belardinelli L, Belloni FL, Rubio R and Berne RM: Atrioventricular conduction disturbances during hypoxia. Possible role of adenosine in rabbit and guinea pig heart. Circ Res 47, 684-691 (1980)

5 Miyamoto K, Takagi K, Sakai R, Wakusawa S, Koshiura R, Nadai $M$, Apichartpichean $R$ and Hasegawa T: Correlation between hydrophobicity of $N$-alkylxanthine derivatives and their biological activities on guinea pig isolated tracheal smooth muscle. J Pharm Pharmacol 41, 844-847 (1989)

6 Sakai R, Konno K, Yamamoto Y, Sanae F, Takagi K, Hasegawa T, Iwasaki N, Kakiuchi M, Kato $\mathrm{H}$ and Miyamoto $\mathrm{K}$ : Effects of alkyl substitutions of xanthine skeleton on bronchodilation. J Med Chem 35, 4039-4044 (1992)

7 Miyamoto K, Kurita M, Sakai R, Sanae F, Wakusawa S and Takagi K: Cyclic nucleotide phosphodiesterase isoenzymes in guinea pig tracheal muscle and bronchorelaxation by alkylxanthines. Biochem Pharmacol 48, 1219-1223 (1994)

8 Miyamoto K, Kurita M, Ohmae S, Sakai R, Sanae F and Takagi $\mathrm{K}$ : Selective tracheal relaxation and phosphodiesterase-IV inhibition by xanthine derivatives. Eur J Pharmacol 267, 317-322 (1994)

9 Miyamoto K, Sakai R, Kurita M, Ohmae S, Sanae F, Sawanishi $\mathrm{H}$, Hasegawa $\mathrm{T}$ and Takagi K: Effects of alkyl substituents of xanthine on phosphodiesterase isoenzymes. Biol Pharm Bull 18, 431-434 (1995)

10 Miyamoto K, Yamamoto Y, Kurita M, Sakai R, Konno K, Sanae F, Ohshima T, Takagi K, Hasegawa T, Iwasaki N, Kakiuchi $\mathrm{M}$ and Kato $\mathrm{H}$ : Bronchodilator activity of xanthine derivatives substituted with functional groups at the 1- or 7position. J Med Chem 36, 1380-1386 (1993)

11 Hopkins SV: The potentiation of the action of adenosine on the guinea pig heart. Biochem Pharmacol 22, 341-348 (1973)
12 Chijiwa T, Mishima A, Hagiwara M, Sano M, Hayashi K, Inoue $T$, Naito $K$, Toshioka $T$ and Hidaka $H$ : Inhibition of forskolin-induced neurite outgrowth and protein phosphorylation by a newly synthesized selective inhibitor of cyclic AMP-dependent protein kinase, $N$-[2-( $p$-bromocinnamylamino)ethyl]-5-isoquinoline-sulfonamide ( $\mathrm{H}-89)$, of PC12D pheochromocytoma cells. J Biol Chem 265, 5267-5272 (1990)

13 Bruns RF, Fergus JH, Badger EW, Bristol JA, Santay LA, Hartman JD, Hays SJ and Huang CC: Binding of the $A_{1}$-selective adenosine antagonist 8-cyclopentyl-1,3-dipropylxanthine to rat brain membranes. Naunyn Schmiedebergs Arch Pharmacol $335,59-63$ (1987)

14 Jacobson KA, Ukena D, Kirk KL and Daly JW: $\left[{ }^{3} \mathrm{H}\right]$ Xanthine amino congener of 1,3-dipropyl-8-phenylxanthine: an antagonist radioligand for adenosine receptors. Proc Natl Acad Sci USA 83, $4089-4093$ (1986)

15 Miyamoto K, Sakai R, Yamamoto $\mathrm{Y}$, Konno K, Sanae F, Hasegawa $T$ and Takagi $K$ : Selective bronchodilators from 1(5'-oxohexyl)xanthines. J Pharm Pharmacol 44, 888-892 (1992)

16 Cheng YC and Prusoff WH: Relationship between the inhibition constant $\left(\mathrm{K}_{\mathrm{i}}\right)$ and the concentration of inhibitor which causes 50 percent inhibition $\left(I_{50}\right)$ of enzyme reaction. Biochem Pharmacol 22, $3099-3108$ (1973)

17 Reeves ML, Leigh BK and England PJ: The identification of a new cyclic nucleotide phosphodiesterase activity in human and guinea pig cardiac ventricule. Biochem J 241, 535-541 (1987)

18 Thompson WJ and Appleman MM: Multiple cyclic nucleotide phosphodiesterase activities from rat brain. Biochemistry 10, $311-316$ (1971)

19 Yamaoka K, Tanigawara Y, Nakagawa T and Uno T: A pharmacokinetic analysis program (MULTI) for microcomputer. $\mathbf{J}$ Pharmacobiodyn 4, 879-885 (1981)

20 Silver PJ, Hamel LT, Perrone MH, Bently RG, Bushover CR and Evans DB: Differential pharmacologic sensitivity of cyclic nucleotide phosphodiesterase isozymes isolated from cardiac muscle, arterial and airway smooth muscle. Eur J Pharmacol 150, $85-94$ (1988)

21 Daly JW: Adenosine receptors. Adv Cyclic Nucleotide Protein Phosphorylation Res 19, 29-46 (1985)

22 Liang BT: Adenosine receptors and cardiovascular function. Trends Cardiovasc Med 2, 100-108 (1992)

23 Dobson JG Jr, Fenton RA and Romano FD: Antiadrenergic actions of adenosine in the heart. In Topics and Perspectives in Adenosine Research, Edited by Gerlach E and Becker BF, pp 356-368, Springer-Verlag, Berlin (1987) 